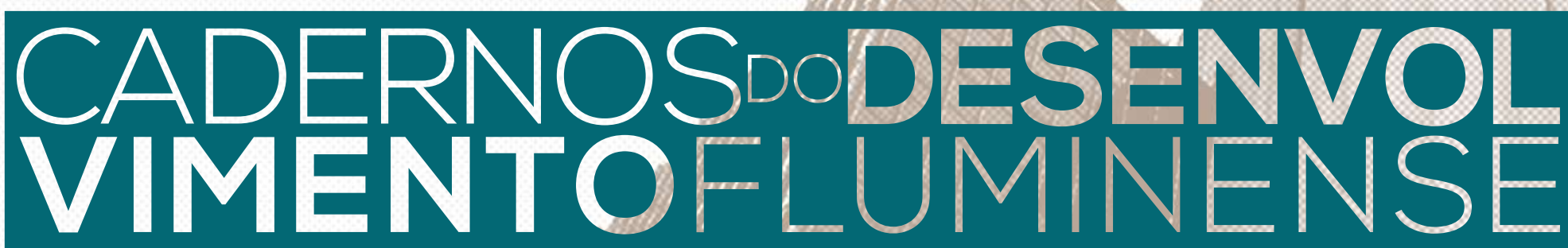

16

ANO $2019 \mid 1^{\circ}$ semestre

- Especialização produtiva - reflexos sobre o

desenvolvimento do estado do Rio de Janeiro;

- Relação entre renda petrolífera e melhoria na

qualidade de vida por municípios

confrontantes da Bacia de Campos;

- Desafios à gestão, ao desenvolvimento sustentável em Miracema;

- Inovação e Desenvolvimento Regional - uma análise sobre a produção científica da Universidade Estadual do Norte Fluminense e sua potencial contribuição para a sociedade;

- Perfil socioeconômico de feirantes do mercado municipal de Campos dos Goytacazes;

- Casa popular própria - ilusão ou solução;

- Capilaridade territorial na provisão de medicamentos básicos no estado do Rio de Janeiro;

- NudgeRio um caso de aplicação de Ciência Comportamental às Políticas Públicas;

- Mulher, política e cidade - reflexões analíticas.
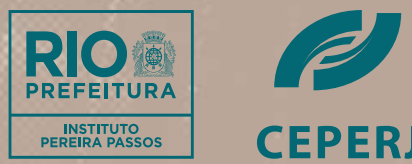


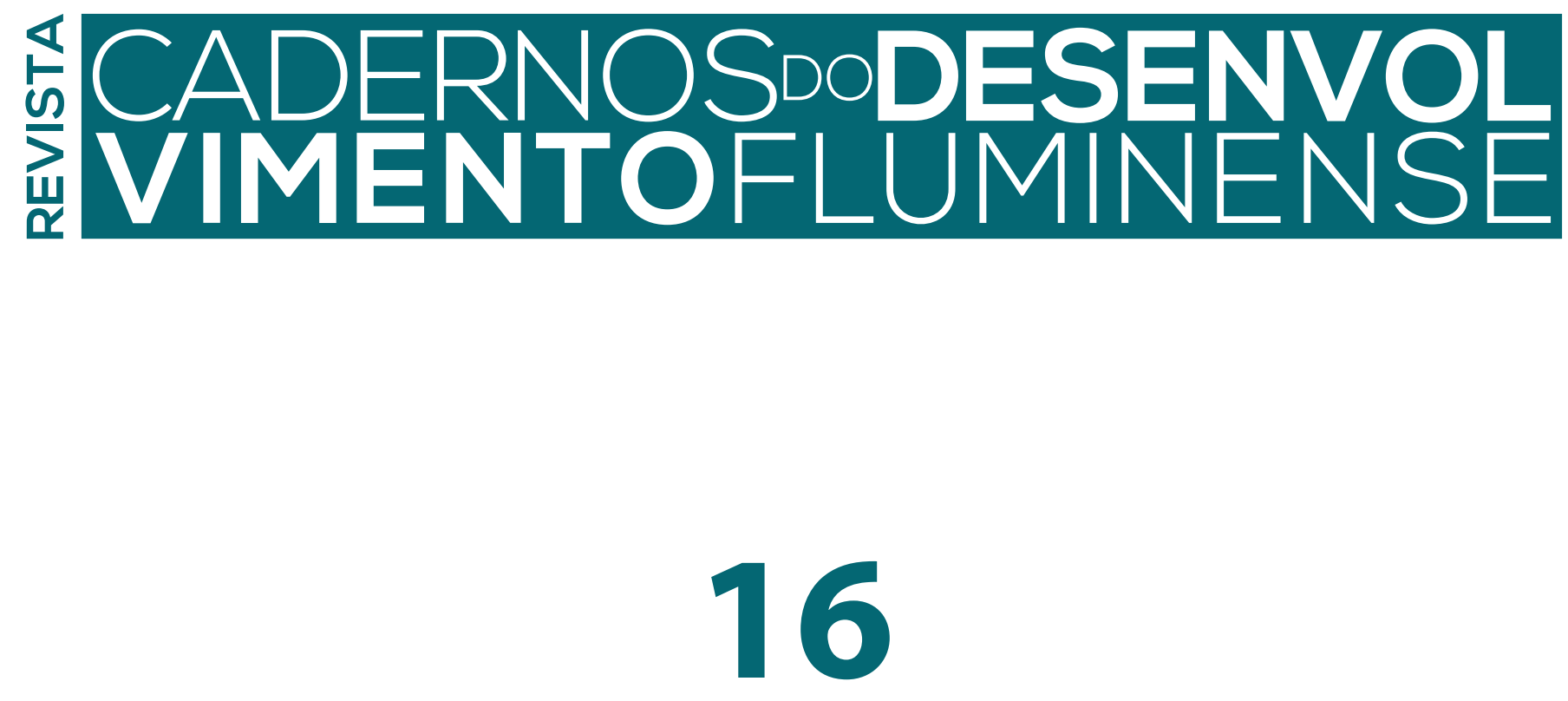

ANO 2019 $\mid 1^{\circ}$ semestre 
FUNDAÇÃO CENTRO ESTADUAL DE ESTATÍSTICAS, PESQUISAS E FORMAÇÃO

DE SERVIDORES PÚBLICOS DO RIO DE JANEIRO — CEPERJ

PRESIDÊNCIA

Pedro Castilho

ESCOLA DE GESTÃO E POLÍTICAS PÚBLICAS

Homero de Araújo Torres

CENTRO DE ESTATÍSTICAS, ESTUDOS E PESQUISAS

Fabio Odilon Alves Gomes

DIRETORIA DE CONCURSOS E PROCESSOS SELETIVOS

Lisandro Junior

DIRETORIA DE COOPERAÇÃO TÉCNICA E DES. INSTITUCIONAL

Tatiani Lisboa

DIRETORIA ADMINISTRATIVA E FINANCEIRA

Marcelo Serrano Peixoto

INSTITUTO PEREIRA PASSOS — IPP

DIRETOR-PRESIDENTE

Mauro Osorio

COORDENADOR TÉCNICO DE INFORMAÇÕES DA CIDADE

Carlos Krykhtyne

COORDENADORA TÉCNICA DE PROJETOS ESPECIAIS

Andrea Pulici

COORDENADOR DE COMUNICAÇÃO

Bruno Filippo 


\section{Editores}

EDITORES CIENTÍFICOS

Jorge Britto • UFF

Lia Hasenclever • Instituto de Economia - UFRJ

EDITOR EXECUTIVO

Bruno Filippo • IPP

\section{CONSELHO EDITORIAL}

Bruno Leonardo Barth Sobral • Faculdade de Ciências Econômicas - UERJ

Carlos Antonio Brandão • Inst. de Pesquisa e Planejamento Urbano e Regional - UFRJ

Fabiano Guilherme Mendes Santos • Instituto de Estudos Sociais e Políticos - UERJ

Glaucio José Marafon • Instituto de Geografia - UERJ

Jorge Nogueira de Paiva Britto • Faculdade de Economia - UFRJ

José Luis Vianna da Cruz • Centro de Pesquisa Candido Mendes - UCM

Lia Hasenclever • Inst. de Economia - UFRJ / Universidade Cândido Mendes

Campos - UCAM Campos

Luis Fernando Valverde Salandía • Instituto Pereira Passos

Luiz Martins de Melo • Instituto de Economia - UFRJ

Maria Alice Rezende de Carvalho • Depto. de Ciências Sociais - PUC RJ

Maria Lucia Teixeira Werneck Vianna • Instituto de Economia - UFRJ

Maria Helena de Macedo Versiani • Instituto Brasileiro de Museus

Marieta de Moraes Ferreira • Fundação Getúlio Vargas

Mauro Osorio • Faculdade Nacional de Direito - UFRJ

wMiguel Antonio Pinho Bruno - Escola Nacional de Ciências Estatísticas - IBGE /Fac. de Ciên-

cias Econômicas - UERJ / Mackenzie Rio

Nelson de Castro Senra • Escola Nacional de Ciências Estatísticas - IBGE

Paulo Alcântara • Universidade Cândido Mendes - UCAM

Paulo Knauss Mendonça • Depto. de História - UFF

Pedro Abramo • Instituto de Pesquisa e Planejamento Urbano Regional - UFRJ

Renata Lèbre La Rovere • Instituto de Economia - UFRJ

Roberto de Andrade Medronho • Instituto de Estudos em Saúde Coletiva - UFRJ

Rosélia Périssé Piquet • Centro de Pesquisa Candido Mendes - UCM

Sergio Ferraz Magalhães • Faculdade de Arquitetura e Urbanismo - UFRJ

Silvia Ramos • Centro de Estudos de Segurança e Cidadania - UCM

\section{REVISTA CADERNOS DO DESENVOLVIMENTO FLUMINENSE}

\section{COORDENAÇÃO}

Bruno Filippo

SECRETARIA EXECUTIVA

Ariana Falcão

REVISÃo

De responsabilidade dos autores

PROJETO GRÁFICO E DIAGRAMAÇÃO

Cláudio Novaes

R. São Francisco Xavier, 524/SI. 1050, Bloco FS - Maracanã

Rio de Janeiro • RJ - CEP 20550-013 - Telefone: (21) 2334-7313

revistacadernos.ceperj@gmail.com | www.e-publicacoes.uerj.br/ojs/index.php/cdf 



\section{Editorial}

Os Editores tem a satisfação de apresentar o conteúdo do $16^{\circ}$ número da REVISTA CADERNOS DO DESENVOLVIMENTO FLUMINENSE, que reflete o compromisso com uma reflexão acadêmica multidisciplinar sistemática tanto sobre contexto sócio-econômico-territorial do estado do Rio de Janeiro (ERJ), como também sobre orientações e práticas relevantes no campo das políticas públicas, orientadas para os enfrentamentos de desafios colocados em função de transformações contemporâneas da sociedade fluminense em suas múltiplas dimensões. Seguindo essa tradição, o presente número contempla tanto artigos baseados em reflexões de natureza mais geral, como abordagens mais focalizadas, em termos tanto do objeto de reflexão como do campo associado das políticas públicas. Traz colaborações de várias instituições do ERJ e abordagens de distintos campos disciplinares.

Em primeiro lugar, cabe destacar artigos com foco mais amplo em termos do diagnóstico socioeconômico do Estado do Rio de Janeiro, seja através de abordagens que contemplam tanto a configuração geral da estrutura produtiva, seja através de análises territorialmente mais localizadas da dinâmica socioeconômica. O artigo “Especialização produtiva: reflexos sobre o desenvolvimento do estado do Rio de Janeiro", de Henrique Cavalieri e Lia Hasenclever, analisa a evolução da estrutura produtiva do Estado do Rio de Janeiro, em comparação com a nacional. Ressalta-se a concentração em segmentos associados ao petróleo e mostra-se que essa especialização produtiva não tem se constituído em uma via de desenvolvimento virtuoso para o estado, pois tende a perpetuar e reproduzir heterogeneidades estruturais, refletidas em tendências de baixo crescimento econômico e vulnerabilidade externa.

No campo de um diagnóstico socioeconômico territorialmente mais localizado, o artigo "Relação entre renda petrolífera e melhoria na qualidade de vida por municípios confrontantes da Bacia de Campos", de Roberto Meireles Acruche, Ítalo de Oliveira Matias, Milton Erthal Jr, Fabio Freitas da Silva e Aldo Shimoya, tem como foco os nove municípios fluminenses pertencentes à Bacia de Campos. Por meio de uma pesquisa que usa o método de análise multicritério e dados do Índice FIRJAN (Federação das Indústrias do Rio de Janeiro) de Desenvolvimento Municipal, classifica os municípios e compara esta ordenação ao montante de rendas petrolíferas recebidas. Aponta-se que maiores níveis de royalties per capita não estão associados a melhores condições de desenvolvimento humano e constata-se uma dependência financeira dos municípios em relação à transferência e royalties acima de $70 \%$, com exceção da cidade de Macaé por concentrar a atividade petrolífera na região, sugerindo-se que a abundância de recursos naturais levou tanto a um afrouxamento fiscal e a uma tendência a negligenciar políticas públicas que estimulassem o desenvolvimento local.

Em sequência, o artigo "Desafios à gestão, ao desenvolvimento sustentável em Miracema (RJ)", de Paulo José de Mendonça Ribeiro, discute os impactos da criação de UC - Unidade de Conservação (UC) no município de Miracema, em 2010 como estratégia para promoção de um município "saudável e sustentável". Foi feita uma pesquisa de campo sobre: problemas de saneamento básico (lixo, esgoto, água e drenagem) e ambientais (erosão, desmatamento, contaminação da água), de modo a verificar em que medida a problemática socioambiental incorpora as questões relativas a qualidade de vida e bem-estar dos indivíduos e coletividades. As evidências coletadas sugerem que há mais custos que benefícios, particularmente no que se refere à sustentabilidade socioambiental, que representa um grande desafio para as políticas públicas.

O artigo "Inovação e Desenvolvimento Regional: uma análise sobre a produção científica da Universidade Estadual do Norte Fluminense e sua potencial contribuição para a sociedade", de Raquel Chaffin Cezario, Edson Terra Azevedo Filho e Henrique Rego Monteiro da Hora, pro- 
cura discutir, com base na experiência da Universidade Estadual do Norte Fluminense Darcy Ribeiro - UENF, o papel da universidade na sociedade, por meio da produção de conhecimento e da capacidade de induzir o desenvolvimento regional via inovação. A metodologia contempla uma abordagem quali-quantitativa mediante pesquisa bibliométrica no Banco de Dados Scopus. Constatou-se que a UENF tem gerado conhecimento relevante, por meio de publicações de documentos, principalmente na área das Ciências Agrárias e Biológicas, apresentando um potencial inovador capaz de contribuir com o desenvolvimento da Região desde que haja engajamento entre ela, governo e empresa, numa Hélice Tríplice.

Considerando um foco mais microscópico na abordagem da problemática do desenvolvimento socioeconômico local, o artigo "Perfil socioeconômico de feirantes do mercado municipal de Campos dos Goytacazes" de Graciela Aparecida Profeta, Raquel Chaffin Cezario, Elen Cristina de Mattos Lima e Vanuza da Silva Pereira Ney, procura caracterizar o perfil socioeconômico de feirantes de hortifrutícolas do mercado municipal de Campos dos Goytacazes, considerando aspectos relacionados aos canais de comercialização e as características econômicas que diferenciam os feirantes. Os resultados obtidos apontam que a renda mensal oriunda da feira era de extrema importância na composição da renda total da família, e, portanto, na sobrevivência das mesmas. Constatou-se também que os feirantes não usavam os circuitos curtos de produção que garantiriam a comercialização da produção local e que isso, além de não lhes fornecer produtos diferenciados para a venda, ainda implicava em perda de receita, pois acabavam competindo em condições desiguais com os supermercados da cidade.

$\mathrm{Na}$ transição entre abordagens de cunho mais analítico e abordagens com foco mais direcionado para a avaliação de políticas, o artigo "Casa popular própria: ilusão ou solução?", de Bianca Siqueira Gonçalves, Livia Maria de Souza Almeida Coura e José Luis Vianna da Cruz, é de natureza essencialmente conceitual, procurando discutir aspectos capazes de nortear a implementação de políticas habitacionais e urbanas, conectando a discussão do sonho de consumo da propriedade de um lugar para morar com as possibilidades de efetivação do direito à cidade, através de um revisão não sistemática da bibliografia sobre a origem da casa como mercadoria e objeto de desejo do trabalhador e sobre a questão da segregação sócio espacial à luz do Direito à Cidade. Ao mesmo tempo, procura-se articular essa discussão a aspectos importantes da estrutura e dinâmica da cidade, ressaltando-se o papel do planejamento urbano no sentido de mitigar a segregação socioespacial.

No campo mais operacional da avaliação de políticas, o artigo "Capilaridade territorial na provisão de medicamentos básicos no estado do Rio de Janeiro", de Eduardo Manhães e Lia Hasenclever, analisa a Política Pública de Assistência Farmacêutica (AF) nas mesorregiões do estado do Rio de Janeiro por meio da distribuição territorial das Unidades Básicas de Saúde (UBS) e dos estabelecimentos do Programa Farmácia Popular do Brasil. Aborda ainda a relação existente entre a instalação de unidades de AF com o volume populacional e a renda média per capita das mesorregiões no ano de 2018. A partir da construção de indicadores e da análise da correlação entre as variáveis, constata-se que, apesar de ter havido uma expansão da provisão de medicamentos, os estabelecimentos da rede credenciada são mais concentrados e os das UBS são mais dispersos no território, o que indica um melhor desempenho destas últimas em termos de distribuição territorial.

Ainda no campo da operacionalização de políticas públicas, o artigo "NudgeRio: um caso de aplicação de Ciência Comportamental às Políticas Públicas", de Otávio Morato de Andrade, discute possíveis soluções para políticas públicas baseadas em insights e fundamentos teóricos da Economia Comportamental, mais conhecidos como Nudges, termo que sugere a associação de incentivos comportamentais para reverter falhas cognitivas e que podem inspirar a criação de novas estratégias de aderência às políticas públicas. Especificamente, procura-se discutir com exemplos práticos de aplicações de Nudges no âmbito da governança estatal, em especial, o caso da NudgeRio, unidade criada na Prefeitura da Cidade do Rio. Refere-se ao caso da implementação do Programa Líderes Cariocas (PLC), coordenado pelo Instituto Fundação João Goulart (IFJG), que procura selecionar servidores públicos com perfil de liderança positiva e capacitá-los para assumir posições proeminentes na administração pública municipal. 
Por fim, no campo mais amplo da representação política, mas ainda com claros desdobramentos na definição de políticas públicas, o artigo "Mulher, política e cidade: reflexões analíticas", de Aimée Seixas de Sousa e María Gabriela Scotto, discute as relações entre mulheres, cidade, feminismo e participação em espaços de representação política. O caso da pesquisa em foco é a presença feminina na Câmara Municipal do Rio de Janeiro. Especificamente, a partir da implementação das cotas eleitorais para mulheres, busca-se discutir as relações entre a participação política e o direito à cidade sob a concepção de gênero. Argumenta-se que, numa perspectiva feminista, é possível pensar a mulher presente e atuante na política municipal como planejadora do espaço urbano e da vida das cidades, avaliando de maneira mais clara suas pretensões, interesses e demandas, apontando-se a necessidade de autonomia feminina no que diz respeito aos seus direitos como cidadãs e às escolhas sobre o acesso e a função do espaço público.

O conjunto de artigos presentes nesse número da REVISTA CADERNOS DO DESENVOLVIMENTO FLUMINENSE reflete o caráter multidisciplinar da discussão sobre o desenvolvimento fluminense e o compromisso em relação à avaliação de políticas públicas que norteiam a nossa linha editorial. Além disso, destacamos o compromisso do Conselho Editorial e das instituições de apoio no sentido de dar maior celeridade à avaliação das submissões e à atualização do processo de edição. É com base nessa perspectiva que reiteramos o convite à comunidade acadêmica para novas submissões que enriqueçam ainda mais a Revista. 



\title{
Perfil socioeconômico de feirantes do Mercado Municipal de Campos dos Goytacazes
} Socioeconomic profile of fairs of the Municipal Market in Campos dos Goytacazes

\author{
Graciela Aparecida Profeta1; Raquel ChaffinCezario²; \\ Elen Cristina de Mattos Lima ${ }^{3}$ e Vanuza da Silva Pereira Ney ${ }^{4}$
}

\begin{abstract}
RESUMO
Esta pesquisa objetivou definir o perfil socioeconômico de feirantes de hortifrutícolas do mercado municipal de Campos dos Goytacazes, no estado do Rio de Janeiro. Para isso foram abordados aspectos relacionados ao canal de comercialização, o perfil e as características econômicas que diferenciam os feirantes, bem como uma pesquisa bibliográfica a fim de encontrar conceitos que possam definir o que seria perfil socioeconômico. Realizou-se ainda uma pesquisa de campo no mercado municipal de Campos dos Goytacazes com os feirantes do segmento hortifrutícolas. De maneira geral, os resultados obtidos apontaram que a renda mensal oriunda da feira era de extrema importância na composição da renda total da família, e, portanto, na sobrevivência das mesmas. Observou-se também que as condições socioeconômicas desses feirantes eram provenientes das atividades no mercado municipal da cidade, e que os feirantes não usavam os circuitos curtos de produção que garantiriam a comercialização da produção local e que isso, além de não lhes fornecer produtos diferenciados para a venda, ainda implicava em perda de receita, pois acabavam competindo em condições desiguais com os supermercados da cidade. Por fim, os feirantes também apontaram a necessidade de maior apoio do poder público para a melhoria das condições e da infraestrutura do local onde desenvolviam a atividade e também suporte no escoamento da produção.
\end{abstract}

PALAVRA-CHAVE: Condições socioeconômicas, feiras municipais, hortifrutícolas, Campos dos Goytacazes, políticas públicas.

\footnotetext{
ABSTRACT

This research aimed to define the socioeconomic profile of fruit and vegetable market vendors at the municipal market of Campos dos Goytacazes, in the state of Rio de Janeiro. For this, aspects related to the commercialization channel, the profile and the economic characteristics that differentiate the marketers were addressed, as well as a bibliographic search in order to find concepts that can define what would be the socioeconomic profile. Methodologically, were done field studies at the municipal market in Campos dos Goytacazes with market vendors in the fruit and vegetable segment. In general, the results demonstrated that the monthly income from the street fair was extremely important in the composition of the family's total income, and therefore in their survival. It was also observed that the socioeconomic conditions of these market traders came from activities at the city's municipal market, and that market traders did not use the direct sale too the consumers circuits that would guarantee the commercialization of the local production and that this, in addition to not providing them with differentiated products for the sale still implied a loss of revenue, as they ended up competing under unequal conditions with the city's supermarkets. Finally, the marketers also pointed out the need for greater support from the public authorities to improve the conditions and infrastructure of the place where they developed the activity and also support in the flow of production.

KEYWORDS: Socioeconomic conditions, municipal fairs, horticultural, Campos dos Goytacazes, public policies. 


\section{Introdução}

O Mercado Municipal de Campos dos Goytacazes (Campos) é uma instituição que possibilita aos indivíduos da sociedade a troca de bens econômicos. Os mercados, de maneira geral, ofertam variedades de produtos e diversidades de preços com o intuito de atrair clientes e satisfazer suas expectativas. No mercado é possível a participação de inúmeras pessoas vendendo ou comprando, de modo a comportar, continuamente, o fluxo dos produtos, sem limites de produtos comercializados, mas sempre segundo uma organização formal e normas institucionalizadas, e uma temporalidade, que pode ser episódica, intermitente, eventual, sazonal ou contínua (FREITAS, 2006).

De acordo com o último levantamento realizado pela administração do mercado municipal de Campos, no final de 2005, no setor de hortifrutícola havia muito mais comerciantes do que pontos de vendas. Segundo os administradores, em apenas uma banca, eventualmente, trabalhava dois ou mais comerciantes, não necessariamente no mesmo dia ou juntos, e que 264 comerciantes detinham uma ou mais bancas, num total de 465 bancas ocupadas e cerca de 25 vagas e algumas outras desmanchadas.

Baseado nos números apresentados acima, bancas e comerciantes (feirantes), pode-se dizer que o mercado municipal de Campos é um espaço de grande importância na vida dos feirantes, pois contribui para a melhoria de vida destes e de suas famílias por meio da renda financeira, e também por ser um espaço de promoção social e cultural, carregada de narrativas e símbolos sociais. Ademais, este ambiente fornece informações sobre as condições de trabalho, a organização e o consumo, a origem e o destino dos produtos, o potencial de comercialização, o nível de satisfação, as organizações locais, enfim, sobre todos os envolvidos no processo, produtores, consumidores, feirantes, etc.

Dada à importância econômica e social do mercado municipal de Campos, é fundamental o entendimento do perfil socioeconômico dos feirantes de hortifrutícolas, de modo a responder os seguintes questionamentos: i) qual é o perfil socioeconômico dos feirantes de hortifrutícolas do mercado municipal de Campos?; ii) como desenvolvem suas atividades no mercado, desde a aquisição dos produtos até a venda?; e iii) estes se enquadram na classe de feirantes produtores ou comerciantes, segundo Sacco dos Anjos et. al. (2005)? Logo, o objetivo deste artigo foi, portanto, estudar o perfil socioeconômico dos feirantes do segmento hortifrutícolas do mercado municipal de Campos dos Goytacazes, para responder a tais questionamentos.

\section{2- Metodologia}

Com vistas a atender aos objetivos da presente pesquisa, foi realizada uma pesquisa bibliográfica a partir de leituras de textos que abordam e discutem os temas feiras e mercados municipais para auxiliar na compreensão do caráter dos mercados e do perfil dos feirantes. Também foram aplicadas entrevistas semiestruturadas para conhecer a realidade das condições socioeconômicas dos feirantes.

Segundo Gil (2002) a pesquisa bibliográfica é desenvolvida com base em material já elaborado, constituído principalmente de livros e artigos científicos. Embora, em quase todos os estudos sejam exigidos algum tipo de trabalho dessa natureza, há pesquisas desenvolvidas exclusivamente a partir de fontes bibliográficas. Boa parte dos estudos exploratórios pode ser definida como pesquisas bibliográficas. Assim, a pesquisa exploratória tem como objetivo proporcionar maior familiaridade com o problema, com vistas a torná-lo mais explícito ou a construir hipóteses. A grande maioria dessas pesquisas envolve: (a) levantamento bibliográfico; (b) entrevistas com pessoas que tiveram experiências práticas com o problema pesquisado; e (c) análise de exemplos que estimulem a compreensão. Essas pesquisas podem ser classificadas como: pesquisa bibliográfica e estudo de caso (GIL, 2007apud GERHARDT et at., 2009).

Em função dessas considerações, o tipo de pesquisa adotado foi o estudo de caso, pelos métodos qualitativos e quantitativos, pois nele o pesquisador geralmente utiliza uma variedade de dados coletados em diferentes momentos, e por meio de diversas fontes de informações. Cabe ressaltar que no estudo de caso o pesquisador deve utilizar diversos instrumentos para a coleta de dados: história de vida, história oral, análise documental e entrevista utilizando roteiro semiestruturado. Por isso, o estudo de caso é uma modalidade de pesquisa amplamente utilizada nas Ciências Sociais Aplicadas, com é o caso da 
ciência econômica. Consiste no estudo profundo e exaustivo de um ou poucos objetos, de maneira que permita seu amplo e detalhado conhecimento, tarefa praticamente impossível mediante outros delineamentos já considerados (GIL, 2002).

\subsection{Procedimentos para obtenção de dados}

Inicialmente, para determinar a população de feirantes do segmento de frutas, verduras, legume e hortaliças (chamado de hortifrutícolas), buscaram-se informações com o administrador do mercado municipal de Campos, o qual respondeu que a feira possuía 466 bancas divididas para 350 permissionários. Vale ressaltar que, embora existissem 466 bancas no mercado municipal, nesta pesquisa considerou-se como população o número de permissionários (feirantes), uma vez que o interesse é determinar o perfil socioeconômico de feirantes de hortifrutícolas. $\mathrm{O}$ administrador forneceu também um percentual para cada segmento: i) $25 \%$ dos permissionários comercializavam frutas, ii) $50 \%$ verduras e legumes, iii) $10 \%$ hortaliças, e, iv) $15 \%$ outros produtos como biscoitos, animais, etc.

Por meio dos dados fornecidos pelo administrador e a partir dessa população de 350 permissionários determinou-se uma amostra para a aplicação das entrevistas. Sendo uma população finita, utilizou-se da Equação (1) conforme Morettin e Bussab (2004), onde a determinação da amostra (n) é com base na estimativa da proporção populacional,

$$
n=\frac{N \times \hat{p} \times \hat{q} \times\left(z_{\alpha / 2}\right)^{2}}{\hat{p} \times \hat{q} \times\left(z_{\alpha / 2}\right)^{2}+(N-1) \times E^{2}}
$$

em que $N$ refere-se ao tamanho da população; $n$ refere-se ao número de indivíduos na amostra; ${ }_{\alpha / 2}$ é o valor crítico que corresponde ao grau de confiança desejado; $\hat{p}$ denota a proporção populacional de indivíduos que pertencem à categoria interessada em estudar; $\hat{q}$ refere-se à proporção populacional de indivíduos que não pertencem à categoria interessada em estudar $\hat{q}=1-\hat{p} ; \mathrm{e}, E$ refere-se à margem de erro ou erro máximo de estimativa e identifica a diferença máxima entre a proporção amostral e a verdadeira proporção populacional $(p)$.

Com o cálculo da amostra realizado a partir da Equação 1, admitindo uma margem de erro de $10 \%$ e um grau de confiança de $95 \%$, e a proporção população de $50 \%$, que é o comum para pesquisas dessa natureza, foi obtida a amostra desses feirantes. Sequencialmente efetuou-se um cálculo de proporcionalidade percentual equivalente a cada segmento, respectivamente, cujos resultados estão expostos na Tabela 1.

TABELA 1 - Amostra de feirantes do mercado municipal de Campos dos Goytacazes por segmentos considerando uma população de 350 permissionários.

\begin{tabular}{|c|c|c|c|}
\hline Segmento & $\%$ & População por segmento & Amostra (n) \\
\hline Legumes e verduras & $50 \%$ & 175 & 22 \\
\hline Hortaliças & $10 \%$ & 35 & 4 \\
\hline Outros & $15 \%$ & 53 & 6 \\
\hline
\end{tabular}

Conforme Tabela 1, depois de calculada a população por segmento, encontrou-se também a amostra (n) para cada um deles. Logo, identificou-se que deveriam ser entrevistados 11 feirantes que atuavam no segmento de frutas, 22 que atuavam no segmento de verduras e legumes, quatro no segmento de hortaliças. Cabe destacar que os seis feirantes enquadrados no segmento de outros não foram entrevistados, pois estes não atuavam no segmento de hortifrutícolas. Então, de fato a amostra utilizada na pesquisa foi de 37 feirantes. 


\subsection{Procedimentos para a entrevista orientada pelo questionário}

As entrevistas foram realizadas no período de junho e julho de 2016 de acordo com as questões previamente definidas e que tinham como objetivo buscar informações referentes a: i) tempo de permanência no mercado; ii) características que diferenciam cada um desses feirantes; iii) perfil socioeconômico, iv) comercialização dos produtos; e, v) demais questões que a literatura apontou como fundamentais para entender as condições socioeconômicas dos feirantes de hortifrutícolas do mercado municipal de Campos dos Goytacazes. O roteiro de entrevista consistiu de perguntas diretas, não havendo necessidade de identificação por parte do feirante, tal como nome do dono ou do próprio entrevistado.

Importante ressaltar que durante as entrevistas ocorreram algumas dificuldades devido à desconfiança dos feirantes de que a pesquisa pudesse ser uma espécie de instrumento de fiscalização a ser usado pela Prefeitura Municipal de Campos. O fato de as entrevistas terem sido realizadas em período de eleições municipais, somado aos questionamentos sobre a renda oriunda da atividade, aumentaram as desconfianças dos entrevistados que, muitas vezes, se mostraram arredios e temerosos em responder às perguntas.

Depois da aplicação dos questionários, realizou-se uma revisão dos mesmos, e verificou-se a consistência das respostas obtidas. Os dados da presente pesquisa foram tabulados no Excel, tratados e analisados por meio do programa estatístico SPSS (Statistical Package for Social Sciences) e no Excel, sendo que as tabelas cruzadas foram feitas no SPSS.

\section{Perfil Socioeconômico de Feirantes de Hortifrutícolas}

O perfil socioeconômico é um tema bastante estudado por várias áreas do conhecimento, entretanto não há uma teoria que defina exatamente o que venha a ser perfil socioeconômico. Neste caso, o que geralmente se observa na literatura são pesquisas que visam relacionar várias características da amostra estudada em busca de identificar e definir um conjunto de informações que se conhece como perfil socioeconômico.

De acordo com os autores Sacco dos Anjos et al (2005), Coêlho (2008), Gomes et al (2013), Fonseca e Brauna (2013) e Rocha et al (2014), entre muitos outros que escreveram sobre perfil socioeconômico com foco em feirantes, o que se observa é a realização de levantamento de informações por meio de pesquisas, relacionando muitas variáveis, tais como: sexo, idade, estado civil, grau de escolaridade, ocupação principal, número de membros da família, renda da família, participação da renda da feira na renda bruta mensal familiar, tipo de feirante etc.

Segundo Sacco dos Anjos et. al. (2005), para efeito de análise, pode-se classificar os feirantes em duas classes fundamentais de acordo com o tipo de produto vendido. O primeiro deles é o feirante produtor, ou seja, aquele que produz parte ou totalidade da mercadoria produzida. Geralmente são produtores familiares de frutas, legumes ou verduras. Já a segunda classe é a que engloba feirante comerciante, que é aquele que adquire toda a mercadoria que comercializa junto a atacadistas da cidade, produtores ou outros intermediários.

Por sua vez, Angulo (2008) também dividiu famílias feirantes em dois grupos. O primeiro agrega feirantes que produzem somente para a subsistência da sua unidade familiar e o excedente é destinado para a venda. Segundo o autor, esses produtores usam a força de trabalho exclusivamente familiar e não acumulam capitais. O segundo grupo é composto por feirantes produtores que usam mão de obra familiar e, às vezes assalariada, e estão em condições de acumular um pequeno capital pela maior eficiência produtiva. Ainda dentro desse segundo grupo pode-se destacar uma parcela que emprega, ao mesmo tempo, uma forma combinada de mão de obra familiar e assalariada, com variadas formas de acumulação de capital. Ademais, eles têm um maior e mais diversificado volume de produção. São produtores que participam do processo produtivo e, às vezes, eles são especializados, o que lhes permitem diferenciar seu produto e ser uma referência para a fixação de preço. 
Para o levantamento do perfil socioeconômico, Sacco dos Anjos et. al. (2005), em seu estudo, aplicaram questionários na feira livre de Pelotas - RS valendo-se de um sorteio aleatório, e descreveram esse perfil utilizando variáveis como faixa etária e gênero, grau de escolaridade, nível de renda familiar, composição familiar, condição ocupacional, proximidade da residência em relação à feira, número de anos como consumidores das feiras, valor gasto na feira. Já Coêlho (2008) procurou caracterizar os feirantes dos municípios de Cascavel e Ocara, em Fortaleza. No seu estudo considerou variáveis como sexo, idade, escolaridade, experiência em feira, motivos que levaram os feirantes a escolher a feira como ocupação, participação em outras feiras, principais produtos vendidos, posse de transportes e tipos de concorrência que feirantes acreditavam enfrentar em seu negócio.

Rocha et al (2010), a partir de dados coletados na feira do produtor de Passo Fundo, no Rio Grande do Sul, realizaram estudo por meio de dois questionários, um aplicado aos feirantes e outro aos consumidores. Os questionários abrangeram questões referentes aos aspectos socioeconômicos dos entrevistados e produtos ofertados na feira. A partir do levantamento foi possível traçar alguns aspectos socioeconômicos dos produtores como idade, tamanho familiar, renda familiar, renda per capita, grau de escolaridade, idade e valor gasto pelos consumidores.

O estudo de Sales et al (2011) foi desenvolvido via realização de uma pesquisa usando métodos qualitativos e quantitativos, com o intuito de definir o que seria o negócio da feira livre, bem como para determinar as principais dificuldades enfrentadas pelos feirantes no exercício da profissão. Como forma de coleta de dados, os autores aplicaram questionários semiestruturados e também fizeram uso da observação não participante revelada. Além disso, os autores consideraram uma distribuição sócia demográfica dos feirantes em Lavras, João Pessoa - Paraíba, de modo a identificar a realidade do negócio desta feira a partir da definição do perfil dos feirantes da cidade e da apreciação das colocações feitas pelos mesmos. Para isso, examinaram variáveis como sexo, cidade natal, faixa etária, estado civil, número de filhos, números de familiares que trabalhavam na feira, se estavam estudando no momento e a renda mensal proveniente da feira. Aspectos motivacionais também fizeram parte da análise, como por exemplo, qual o motivo que levou o entrevistado a escolher a profissão de feirante e as maiores dificuldades encontrado no exercício das atividades. De maneira geral, segundo os autores, constatou-se que, embora bastante satisfeitos com a profissão e com o ambiente de trabalho, os feirantes ainda esbarravam em dificuldades estruturais no seu cotidiano.

Fonseca e Brauna (2013) realizaram uma revisão bibliográfica. Utilizaram dados primários obtidos por meio de entrevista direta e o método da estatística descritiva para análise tabular dos dados referentes às variáveis que descreveram o perfil socioeconômico dos feirantes, a fim de traçar o perfil socioeconômico dos feirantes de Araguaína, Parnaíba - Piauí, e utilizaram as seguintes variáveis: faixa etária, escolaridade, experiência média na atividade como feirante, estado de origem, participação da renda da feira na renda bruta mensal familiar. A partir da pesquisa, os autores verificaram que o espaço onde a feira livre deste município acontecia, ou seja, o local da feira passava despercebido por muitas administrações municipais e isso gerava diversos problemas em relação à infraestrutura, processos de comercialização, limpeza, segurança, organização e fiscalização. No entanto, segundo os autores, mesmo com todos os problemas existentes, a feira livre de Araguaína configurava-se num importante centro de comercialização de produtos agropecuários que gerava externalidade positiva para o município.

Já no estudo de Gomes et al (2013), os autores partiram de uma pesquisa do tipo exploratório-descritivo, com a utilização de um método empírico, no qual o instrumento utilizado para a coleta de dados foi um questionário estruturado, que facilitou a coleta e a tabulação das informações, e usaram também da observação não participante. Ainda como fonte secundária de informações, utilizaram a pesquisa documental. Assim, os autores puderam conhecer a realidade socioeconômica e empresarial de mulheres que atuavam na Central de Abastecimento de Edmundo Flores, em Vitória da Conquista - Bahia. Para alcançar os objetivos, os autores buscaram informações que possibilitaram uma visão mais ampliada dos negócios lá existentes. Os resultados indicaram que as mulheres questionadas e observadas muitas vezes apresentavam-se como mantenedoras de seus lares e que a opção por se tornarem feirantes, em muitos casos, surgiu da necessidade de sustentar seus lares. 


\section{Comercializações da Produção Agrícola Familiar: a Importância da Feira Livre}

De acordo com Freitas (2006), os primeiros mercados que apareceram na história da humanidade funcionavam por meio de trocas. Com o aparecimento do dinheiro começaram a surgir códigos de comércio. Por sua vez, o aumento da produção resultou no aparecimento de intermediários entre os produtores e os consumidores finais. É neste ambiente, onde ocorrem as trocas de bens e serviços entre ofertantes (vendedores) e demandantes (compradores), que se estabelecem as relações comerciais com o objetivo de realizar transações, acordos ou trocas.

O caminho percorrido por um produto, desde o momento da sua produção até a sua disponibilização ao consumidor final pode passar por uma série de atividades distintas. Nesse caminho a matéria-prima sofre várias transformações operadas por intermediários, e em cada uma dessas transformações são repartidos os valores que vão sendo acrescentados aos produtos originados. Ou o caminho pode ser mais curto, chamado de circuito curto de comercialização, no qual o produtor vende diretamente seus produtos ao consumidor, independente se transformado ou não (MODEL e DENARDIN, 2014). Os circuitos curtos permitem que a produção e o consumo se deem no mesmo território, beneficiando a cidade ou região.

Segundo Model e Denardin (2014), a comercialização em circuitos curtos traz vantagens econômicas, sociais e culturais, desenvolve condições para práticas de reciprocidade por meio de trocas e favores realizados entre vizinhos, impulsiona a criação de associações e cooperativas pela necessidade de formalização das relações, e promove o desenvolvimento local, alterando a dinâmica social e econômica com uma maior circulação de renda, serviços e produtos. Algumas formas de exploração de circuitos curtos são a venda de porta em porta, as feiras livres, as cooperativas agrícolas e também alguns programas como o PAA - Programa de Aquisição de Alimentos do Governo Federal ${ }^{5}$.

Durante a maior parte da história brasileira, a agricultura familiar ${ }^{6}$ foi um segmento quase inteiramente esquecido pelo Poder Público. A modernização da agricultura se deu em detrimento desse segmento, uma vez que as políticas públicas privilegiaram os produtores mais capitalizados que procuraram investir na esfera produtiva de commodities voltadas ao mercado internacional, com fins de corrigir os desequilíbrios dos pagamentos externos do país (MATTEI, 2001; DELGADO, 2005). Quanto à comercialização de produtos agrícolas oriundos da produção da agricultura familiar, sabe-se que as feiras livres se constituem como um dos principais canais de comercialização desses produtos e que raramente esses pequenos produtores recebem apoio de políticas públicas específicas, ou são objetos de programas de desenvolvimento rural, a exceção do crédito rural via Programa Nacional de Fortalecimento da Agricultura Familiar (PRONAF) que se destina ao custeio da produção e ao investimento (PIERRI e VALENTE, 2010).

De acordo com Wilkinson (2008), novos mercados podem ser formados pela agricultura familiar à medida que apresentarem relação com o tradicional, com a natureza, com o artesanal e com o local, pois estas são propriedades que podem trazer diferencial à atividade e, portanto, vantagem estratégica. A feira livre é, neste contexto, uma boa alternativa de escoamento dessa produção familiar, pois garante uma renda semanal aos agricultores, sem a intervenção dos atravessadores, e que, com a comercialização direta, podem conseguir preços melhores.

As feiras livres constituem uma das formas mais tradicionais e antigas de comercialização de produtos e permite que o feirante tenha uma relação direta com o consumidor final, o que possibilita a interferência desse na oferta do produto e na precificação dos mesmos (COÊLHO e PINHEIRO, 2009). Logo, ressalta-se que a comercialização direta de produtos agrícolas numa feira livre é parte essencial de toda a cadeia produtiva. É nela que os esforços de aumento da produtividade e redução de custos no processo produtivo podem ou não ser concretizados.

5 Programa de aquisição de alimento do governo federal, o programa estimula a comercialização de produtos dos agricultores familiares, estimulando a produção e gerando renda.

6 Segundo Wanderley (1995) o conceito da agricultura familiar como categoria genérica é entendido como sendo aquele em que a família, ao mesmo tempo em que é detentora dos meios de produção, também assume o trabalho na atividade. Esta combinação entre propriedade e trabalho, no entanto, assume no tempo e no espaço uma grande diversidade de formas sociais. 
Vale dizer que as feiras, ao ofertarem produtos adaptados aos hábitos culturais locais, proporciona um diferencial em relação aos produtos provenientes das centrais de distribuição. Ou seja, "os produtos ofertados nas feiras, que são ligados aos costumes e à alimentação local, na maioria das vezes não são ofertados por redes varejistas maiores" (SILVESTRE, RIBEIRO e FREITAS, 2011, p.189). Outro diferencial das feriras livres se dá na qualidade dos produtos ofertados. Segundo Nardini et al $(2017$, p.8), estes geralmente "são colhidos antes do raiar do dia e são levados diretamente às bancas das feiras, sem longos períodos de transporte e armazenamento, etapas que contribuem para acumular danos aos produtos" e, portanto, reduz a qualidade física, sensorial e mesmo nutricional dos mesmos. Ademais, segundo Angulo (2003), as feiras proporcionam a valorização da produção agroalimentar, principalmente em municípios de pequeno e médio porte. “Existe toda uma série de diferenças produtivas e culturais entre os feirantes que determinam diferentes relações sociais e diferentes racionalidades econômicas" (ANGULO, 2003, p. 101).

Por outro lado, Nardini et al (2017) afirmam que a estrutura de comercialização centralizada nas Centrais de Abastecimento (CEASAs), impõe um aspecto negativo na complexidade da cadeia de comercialização entre o produtor e o consumidor, uma vez que devido à pequena produção do agricultor familiar, ele se vê sem alternativa, a não ser vender sua produção a um intermediário que detém recursos mais eficientes para o escoamento da produção, e este ator realiza o armazenamento e transporte de uma quantidade maior de produtos, podendo abastecer outros mercados, mas, inclusive, as CEASAs. Por sua vez, nas CEASAs, os produtos são vendidos a outros intermediários, que muitas vezes têm o papel apenas de comerciante e este, por sua vez, repassa os produtos ao mercado varejista local que então vende ao consumidor final.

Por fim, Nardini et al (2017) constataram que parte dos produtos comercializados na feira analisada em seu estudo são adquiridos no varejo, e isto implica em questionar se de fato estas têm funcionado em um sistema de circuitos curtos que se caracterizam como produção e venda direta dos produtos ao consumidor. Nardini et al (2017) também afirmaram que na literatura sobre o tema há uma corrente que admite a existência de um intermediário, que é o que descaracteriza a feira como circuito curto. Então, nota-se que as feiras livres convencionais vêm sendo transformadas em apenas pontos de comercialização de produtos não oriundos da agricultura familiar, principalmente nas grandes cidades, uma vez que a maioria dos feirantes é comerciante que revendem produtos comprados em CEASAS (Centrais de abastecimento).

\section{Resultados e Discussões}

\section{1- Características gerais dos feirantes do mercado municipal de Campos dos Goytacazes}

Para a caracterização dos feirantes foram consideradas variáveis como: sexo, idade, escolaridade, tempo de trabalho na feira, lugar de origem, o que os levou a seguir nesta atividade, como adquiriram a banca, quantidades de bancas, se exerciam outra atividade remunerada, se participavam de outra feira e se eram produtores. A partir dos resultados, observou-se que $64,9 \%$ dos feirantes que atuavam no mercado Municipal de Campos eram do sexo masculino contra 35,1\% do sexo feminino. Entretanto, destaca-se que muitos desses comerciantes do sexo masculino afirmaram que recebiam ajuda de suas esposas nas atividades da feira.

Com relação à idade, $51 \%$ afirmaram ter até 40 anos, o que indicou a existência de um tempo de vida útil para que a atividade da feira permanecesse como fonte de renda dessas familias. Entre os demais, $43 \%$ disseram ter entre 40 e 60 anos e $5 \%$ alegaram ter mais de 60 anos. Os feirantes mais jovens tinham entre 18 e 20 anos, enquanto os mais idosos, 59 e 78, e a média de idade dos feirantes era de 41,19 .

Quanto à escolaridade, os feirantes que possuíam grau de instrução equivalente ao $2^{\circ}$ grau incompleto oucompleto correspondiam à maior proporção (51\%), se comparado com os demais, e isto evidencia o baixo nível de qualificação profissional que esta atividade exige, o que por um lado acaba permitindo que pessoas com baixa escolaridade tenham acesso a um meio de renda; mas, por outro lado, pode retratar a dificuldade desses feirantes de se inserirem em outros setores produtivos, o que os deixava dependentes dessa atividade. Contudo, há de se considerar que o trabalho na feira requeria 
que o feirante tivesse conhecimentos básicos de matemática para poder gerenciar suas vendas, além de outras habilidades como boa capacidade de comunicação para negociar com seus fornecedores e clientes, e experiência neste tipo de comérico, o que poderia ser um pre-requisito fundamental para o sucesso do negócio.

Em relação aos anos de experiência dos feirantes na atividade, verificou-se que $43 \%$ dos entrevistados afirmaram que tinham cerca de 15 anos ou mais de experiência na feira, seguido de 19\% que possuíam menos de dois anos de experiência. Ainda de acordo com os resultados obtidos, a experiência mínima era de um ano, a máxima era de 51 anos e, em média, os feirantes da amostra apresentavam 17 anos de experiência na atividade que exerciam no mercado municipal de Campos.

Quanto aos motivos que levaram os feirantes a seguir esta atividade, $43,2 \%$ relatou-se que os principais foram o desemprego/necessidade em virtude de uma eventual inexistência de melhores oportunidades de trabalho e a perda do emprego formal por alguma razão. Os outros $40,5 \%$ afirmaram que seguiam a tradição familiar ou tinham herdado esta atividade de terceiros. Destaca-se que os demais motivos que os feirantes apontaram como fatores de inserção na atividade da feira estavam relacionados com o gosto pelo trabalho, entre outros, como por exemplo, a indicação.

Sobre o local de origem dos feirantes, $75,7 \%$ dos entrevistados afirmaram que eram naturais de Campos, enquanto $24,3 \%$ disseram ter nascido em outros municípios vizinhos e até mesmo em outros estados, como Pernambuco e São Paulo. Quanto ao tempo de residência em Campos, 78\% dos entrevistados afirmaram que já moravam no município a cerca de 40 anos, enquanto $38 \%$ dos feirantes disseram que já havia mais de 40 anos que residiam na cidade. Na média, os feirantes residiam em Campos há cerca de 36 anos.

\section{2- Caracterização da atividade na feira do mercado municipal de Campos dos Goytacazes}

Das características gerais das bancas de cada feirante e como as adquiriram, e se trabalhavam sozinhos ou não, os resultados das entrevistas semiestruturadas mostraram que, dos 37 feirantes que fizeram parte da amostra, $86,5 \%$ eram proprietários das bancas e 13,5\% não eram donos do negócio. Logo, a maioria trabalhava por conta própria, e isso pode ser fruto do fato de mais de $80 \%$ dos entrevistados terem ingressado na atividade por necessidade/desemprego ou por terem herdado o negócio.

Quando perguntados como adquiriram a banca, 62,2\%, que representam 23 dos 37 feirantes entrevistados, disseram que receberam como herança de família; os demais alegaram que haviam comprado ou pagavam aluguel (taxa do uso do solo), ou ainda que foi via parentes, doação, permissão do uso do solo. Cabe destacar que todos os feirantes, para exercerem suas atividades na feira, deveriam possuir esta permissão do uso do solo, uma vez que as instalações no mercado municipal são consideradas patrimônio público. Em tempo, vale dizer que na época da realização das entrevistas não se pagava para ter tal permissão.

Sobre a forma de trabalho, observou-se que a maioria, 59,5\%, preferia trabalhar com parentes e isso pode ser devido ao maior grau de confiança nos mesmos do que em terceiros, mesmo porque a contabilidade (estoque de mercadorias e caixa, por exemplo) geralmente não era formalizada, o que dificultava ter informações fidedignas dos resultados obtidos com a atividade. Entre os demais, 32,4\% disseram que trabalhavam sozinhos e $8,1 \%$ afirmaram que possuíam ajudantes/ funcionários.

No que concerne à distribuição do número de bancas por feirante/proprietário e àrenda mensal oriunda da atividade na feira do mercado municipal de Campos dos Goyacazes, os resultados apontaram que $72,9 \%$ dos feirantes entrevistados possuíam de uma a três bancas; $18,9 \%$, o que corresponde a sete feirantes da amostra, disseram que eram donos de quatro bancas; e $8 \%$ possuím mais de quatro bancas. Vale ressaltar que $26,9 \%$ afirmaram que tinham quatro ou mais bancas dentro do mercado municipal. Tal situação poderia trazer problemas na estrutura desse sistema de mercado, uma vez que, provavelmente, tais feirantes podiam influenciar, por exemplo, nos preços 
finais dos produtos vendidos e eventualmente se beneficiarem do fato de terem, aparentemente, maior poder econômico que os demais, principalmente aqueles que ou não eram donos ou possuíam apenas uma banca.

Quanto à renda líquida mensal oriunda da atividade da banca, 35,1\%dos feirantes entrevistados afirmaram que recebiam de meio a um salário mínimo, 32,4\% de um a dois salários mínimos, 27\% de dois a três salários mínimos, 2,7\% de três a quatro salários mínimos e 2,7\% acima de quatro salários mínimos. Além disso, os dados coletados permitiram verificar que a renda mensal líquida da feira era, em média, de três salários mínimos, o que representava em termos de valores em 2016 (data da pesquisa), $\mathrm{R} \$ 2.640,00$ (dois mil e seiscentos e quarenta reais).

Em relação à jornada de trabalho, os feirantes, em sua maioria, trabalhavam mais de doze horas por dia, todos os dias da semana, incluindo os sábados e domingos, quando a feira ficava aberta até às quartoze horas. Importante ressaltar que o mercado funcionava de madrugada, pois era quando chegavam algumas mercadorias. Sendo assim, dado que o feirante trabalhava todos os dias da semana, sua renda líquida média diária era de $R \$ 88,00$ (oitenta e oito reais), e sua atividade pode ser considerada como um trabalho árduo, mal remunerado e que retrata, de modo geral, o pouco grau de instrução dos feirantes.

Das características gerais da comercialização da produção, foi possível verificar que $86,5 \%$ da produção vinha de fornecedores de fora do município, e 13,5\% de produtores rurais tanto de fora como do próprio município de Campos dos Goytacazes-RJ. Dos feirantes entrevistados, apenas um produzia suas próprias mercadorias e as vendia no mercado. Ele produzia frutas e trabalhava com seu pai no sítio da família, e afirmou que não possuíam empregados, e que seguiam esse trabalho que era herança de família e que gostavam do que faziam.

Os feirantes relataram que as hortaliças oferecidas nas bancas da feira eram, na sua grande maioria, oriundas de Nova Friburgo, Teresópolis e Petrópolis (região serrana do estado do Rio de Janeiro) e as verduras e legumes eram do CEASA do Rio de Janeiro, Vitória, São Paulo, Nova Friburgo e Teresópolis. Já as frutas vinham de outros mercados como Rio de Janeiro, Teresópolis, Nova Friburgo, São Paulo, Bahia e Vitória. Afirmaram também que havia uma produção regional, porém em menor proporção e em qualidade inferior devido às condições climáticas locais, como as altas temperaturas.

Devido à origem da produção, a pesquisa apontou para o fato de que os feirantes podiam ser classificados como comerciantes, visto que a maioria deles não produzia o que vendiam. E que, embora a feira livre tenha se mostrado uma boa alternativa ou até mesmo única fonte de renda da maior parte dos feirantes, esta não incentivava o escoamento da produção local, e, ou permitia a entrada de atravessadores nesse segmento, e com isso, perdia-se a oportunidade de comercialização direta entre produtor e consumidor e por consequência a redução dos preços e aquisição de produtos de melhor qualidade em termos de menor tempo de estocagem.

Como já exposto neste texto, o caminho percorrido por um produto, desde o momento da sua produção até a sua disponibilização ao consumidor final, pode ser realizado por uma série de atividades distintas, nas quais a matéria-prima sofre várias transformações operadas por intermediários, e que a cada transformação são repartidos os valores acrescentados aos produtos. Ou pode chegar ao consumidor por meio do circuito curto de comercialização no qual o produtor vende diretamente seus produtos ao consumidor, independente se transformado ou não (MODEL e DENARDIN, 2014). Assim, os circuitos curtos permitem que a produção e o consumo se deem no mesmo território, beneficiando a cidade ou região, o que não estava sendo devidamente aproveitado no caso dos feirantes que operavam no mercado municipal de Campos, pois apenas um feirante relatou que vendia produtos por ele próprio produzido. Ou seja, apenas ele se beneficiava do circuito curto de comercialização.

No que tange ao transporte dos produtos até o mercado municipal para serem vendidos, os resultados mostraram que $97,3 \%$ dos produtos vendidos na feira eram transportados pelo fornecedor até o mercado municipal. Os feirantes afirmaram que os produtos eram trazidos em caminhões conforme a necessidade de reposição do estoque, e que isso geralmente ocorria no início da 
manhã. Informaram, porém, que muitos não tinham horário para chegar, então podia haver descarregamento a qualquer hora do dia. Afirmaram também que a área de estoque desses produtos era um espaço no próprio mercado, e que havia segurança para garantir que as mercadorias não fossem roubadas. Nesta área de estoque era feita a separação e distribuição dos pedidos dos feirantes.

Dos produtos que sobravam, $43,2 \%$ afirmaram que estocavam, enquanto $21,6 \%$ disseram que doavam para pessoas necessitadas, abrigos, entre outros, e 35,1\% relataram que guardavam, ou doavam, ou jogavam fora, pois nem todos os produtos permitiam o reaproveitamento. Cabe destacar que o fato de mais de $21,6 \%$ dos feirantes afirmarem que doavam as sobras daquilo que não conseguiam vender, mostra a função social da atividade do feirante e reforça a importância social dos feirantes do mercado municipal de Campos.

Da participação em outra feira, apenas um feirante afirmou que fazia parte de outra além da localizada no mercado municipal, contudo, não informou o local da mesma. Ele alegou que participava de outra feira com o intuito de aumentar sua renda. Os demais feirantes, isto é, 97,3\% dos entrevistados, disseram que a feira tomava muito tempo e, por isso não participavam de outras, ou afirmaram que não tinham interesse. Dos 37 entrevistados, todos tinham a feira como sua ocupação principal, no entanto, cinco disseram que tinham ocupação secundária, dois deles em relação à própria feira e os outros três não especificaram. Quatro feirantes afirmaram que tinham outra atividade, sendo um produtor rural, dois trabalhadores do sítio e um trabalhava em lanchonete, contudo informaram que a feira era a ocupação principal. Esses resultados demonstram que a atividade na feira do mercado municipal era importante para a composição da renda familiar do feirante.

No que tange à decisão de preço, a maior parte dos entrevistados, representada por $94,6 \%$, afirmou que determinavam o preço dos produtos que vendiam conforme o preço que pagavam ao fornecedor, isto é, de acordo com as condições da compra. Neste caso, vale destacar que o fato de a maior parte não fazer uso dos circuitos curtos de comercialização e depender de intermediáriso, implicava em pelo menos dois problemas: preço ao consumidor final mais alto e redução da margem de lucro dos feirantes. Disseram também que normalmente usavam uma margem de ganho de $30 \%$, mas que às vezes era necessário reduzir para até $5 \%$, de modo a conseguirem preços competitivos e fazerem frente aos supermercados da cidade, que segundo eles, possuíam, muitas vezes, uma melhor estrutura. Isso também pode indicar que o fato de os feirantes dependerem de atravessadores e comprarem em menor escala comparando com os supermercados da cidade, fazia com que os feirantes tivessem menor oportunidae de auferir lucro. Importante destacar que os supermercados de Campos, na época da pesquisa e ainda hoje, operam com escala maior, pois estão estruturados em redes, tendo diversas lojas na própria cidade ou são grandes hipermecados que têm lojas espalhadas por todo o país ${ }^{7}$.

Os feirantes entrevistados afirmaram ainda que muitas vezes eram obrigados a diminuirem seus preços devido ao fato de os próprios colegas feirantes, que vendiam os mesmos produtos, não seguirem um padrão de preço, o que os levavam a competir entre si por fregueses. Por fim, 2,7\% disseram que determinavam o preço de acordo com a necessidade, e outros $2,7 \%$ seguiam os demais feirantes.

Outra questão importante abordada na pesquisa teve o intuito de levantar informações que permitissem entender se os feirantes de hortifrutícolas do mercado municipal de Campos recebiam algum tipo de assistência por parte da prefeitura municipal. Os resultados apontaram segundo $67,6 \%$ dos feirantes entrevistados, que a prefeitura municipal de Campos não fornecia nenhum tipo de assistência. Os outros 32,4\% disseram que a prefeitura dava assistência com relação à água, luz, local cedido, estrutura, segurança. Contudo, alegaram que as condições de limpeza e higiene do mercado eram muito precárias, e isto implicava em perdas de clientes. Este é outro fato que merece destaque, uma vez que a comercialização de produtos locais (circuitos curtos) deveria ser uma questão de política pública, pois, conforme revisão da literatura, as feiras, quando bem exploradas, se mostram como um caminho eficiente para gerar renda e riqueza à população local. 
Na pesquisa foram abordadas também quais eram as melhorias que os feirantes consideravam necessárias para garantir condições mais adequadas de trabalho e atrair novos clientes. Com 35,1\%, apareceu em primeiro lugar a necessidade de um estacionamento para conforto dos clientes e dos próprios feirantes. A esse respeito, os entrevistados alegaram que o fato de que competiam com outros estabelecimentos que vendiam as mesmas mercadorias que eram ofertadas na feira, mas que dispunham de estacionamento acabava por levar os fregueses a preferirem ir a esses locais a frequentarem a feira.

Em segundo lugar, com $24,3 \%$ das respostas, apareceram categorias, como por exemplo, limpeza/ organização e estacionamento/estrutura. Na terceira posição, com 21,6\%, ficou a limpeza e a organização. Outro ponto levantado e que apareceu na quarta posição, com $8,1 \%$ das respostas, foi a necessidade de reforma e também de contribuição dos próprios feirantes com a conservação do ambiente de trabalho, e a necessidade de educação recíproca. Por fim, em quinto lugar, com 2,7\%, os feirantes afirmaram que a administração do mercado deveria dar mais assistência em relação à atividade da feira, o que corrobora o fato de que talvez falte uma política pública focada nesse segmento.

\section{3- Condições socioeconômicas dos feirantes de hortifrutícolas que atuavam no mercado municipal de Campos dos Goytacazes-RJ}

É relevante entender a relação entre a renda auferida com a feira e o número de bancas que cada feirante declarou possuir. Os resultados da distribuição de frequência destas informações que mostram a relação entre o número de bancas e renda auferida da feira foram apresentados na Tabela 2.

TABELA 2 - Distribuição de frequência da relação entre número de bancas e renda mensal dos feirantes oriunda da atividade na feira, 2016.

\begin{tabular}{|c|c|c|c|c|c|c|c|}
\hline & & \multicolumn{5}{|c|}{ Renda Mensal } & \multirow{2}{*}{ Tota } \\
\hline & & 1/2 a 1 s.m & 1 a 2 s.m. & 2 a 3 s.m. & 3 a 4 s.m. & $>5 \mathrm{s.m}$ & \\
\hline \multirow{7}{*}{$\begin{array}{l}\text { NÚMERO DE } \\
\text { BANCAS }\end{array}$} & 1 & 7 & 3 & 0 & 0 & 0 & 10 \\
\hline & 2 & 2 & 5 & 4 & 1 & 0 & 12 \\
\hline & 3 & 0 & 1 & 3 & 0 & 1 & 5 \\
\hline & 4 & 3 & 2 & 2 & 0 & 0 & 7 \\
\hline & 5 & 0 & 0 & 1 & 0 & 0 & 1 \\
\hline & 7 & 0 & 1 & 0 & 0 & 0 & 1 \\
\hline & 10 & 1 & 0 & 0 & 0 & 0 & 1 \\
\hline TOTAL & & 13 & 12 & 10 & 1 & 1 & 37 \\
\hline
\end{tabular}

Fonte: Elaboração própria a partir dos resultados da pesquisa. Nota: s.m. significa salário mínimo.

Conforme Tabela 2, dos feirantes que possuíamuma banca, sete deles relataram receber entre meio e um salário mínimo mensal da feira, enquanto três disseram que recebiam entre um e dois salários minímos. Dos que tinham duas bancas na feira, dois recebiam entre meio e um salário minímo, cinco afirmaram que a feira rendia entre um e dois salários mínimos, quatro recebiam entre dois e três salários mínimos, e apenas um afirmou que recebia entre três e quatro salários mínimos. Quanto aos feirantes que tinham três bancas, notou-se que a maior parte deles (três de cinco) relataram que recebiam entre dois e três salários mínimos mensaisoriundos da feira. Dos que declararam ter quatro ou mais bancas, notou-se que a renda era de até dois salários mínimos. Em tempo, o feirante que disse ter 10 bancas, também disse que recebia entre meio e um salário mínimo mensal. Resultado fora do padrão e que sinaliza que,em se tratando da variável renda, muitas vezes os declarantes temem em fornecer a real informação. Por isso, as observações quanto às respostas dessa questão devem ser consideradas com cautela. 
Outra questão relevante que merece atenção é a relação entre a renda total familiar do feirante e a renda auferida com a atividade na feira. Os resultados deste cruzamento de informações estão apresentados na Tabela 3.

TABELA 3 - Distribuição de frequência da relação entre a renda total familiar e a renda auferida da atividade na feira de hortifrutícolas do mercado municipal de Campos dos Goytacazes-RJ, 2016.

\begin{tabular}{|c|c|c|c|c|c|c|}
\hline & & \multicolumn{4}{|c|}{ Renda total da família } & \multirow[b]{2}{*}{ Total } \\
\hline & & $\begin{array}{c}\text { De } 1 \text { a } 2 \\
\text { S.m (R\$800 } \\
\text { a 1600) }\end{array}$ & $\begin{array}{c}\text { De } 2 \text { a } 3 \text { s. } \\
\text { m.R\$1600 } \\
\text { a 2400) }\end{array}$ & $\begin{array}{l}\text { Mais de } 4 \text { s. } \\
\text { m. }(\operatorname{R} \$ 3520)\end{array}$ & $\begin{array}{l}\text { Não soube } \\
\text { ou não quis } \\
\text { responder }\end{array}$ & \\
\hline \multirow{2}{*}{$\begin{array}{l}\text { RENDA } \\
\text { EXTERNA }\end{array}$} & SIM & 3 & 1 & 3 & 0 & 7 \\
\hline & NÃO & 12 & 11 & 6 & 1 & 30 \\
\hline TOTAL & 15 & 12 & 9 & 1 & 37 & 37 \\
\hline
\end{tabular}

Fonte: Elaboração própria a partir dos resultados da pesquisa. Nota: s.m. significa salário mínimo.

Conforme análise dos resultados apresentados na Tabela 3, o que se observou foi que apenas sete dos feirantes entrevistados recebiam renda extra, enquanto os outros 30 afirmaram que não recebiam nenhum outro tipo de renda a não ser o obtido com o trabalho na feira. Dos que afirmaram receber renda extra, três recebiam entre um e dois salários mínimos mensais e os outros três afirmaram que recebiam mais de quatro salários mínimos mensais, e apenas um declarou que recebia entre dois e três salários mínimos mensais. Por outro lado, dos que afirmaram não receber renda extra, 12 recebiam entre um e dois salários mínimos mensais, 11 alegaram que ganhavam entre dois e três salários mínimos mensais, seis relataram que recebiam mais de quatro salários mínimos mensais e apenas um não soube ou não quis responder qual era a renda da família. Portanto, de acordo com os resultados apresentados na Tabela 3, o que se pode notar é que a atividade na feira do mercado municipal de Campos foi capaz de permitir ao feirante que não possuía renda extra, obter rendimento total familiar igual, ou até mesmo superior, aos que tinham renda extra.

Isso sinaliza dois pontos. O primeiro deles é que a renda da feira depende da capacidade do feirante em comprar seus produtos com qualidade e preço mais baixo e com isso obter maior volume de venda e, consequentemente maior rentabilidade. Por outro lado, pode mais uma vez denotar alguma incongruência de informações por parte dos feirantes e, muitas vezes isso pode ocorrer por desconhecimento do que realmente ele recebe de renda e qual é a fonte, ou por ocultar informações como um mecanismo de defesa.

Cabe mencionar também a relação entre a renda total familiar e a contribuição da renda auferida com a feira. Para tanto, apresentou-se na Tabela 4 os resultados deste cruzamento de informações.

TABELA 4 - Distribuição de frequência da relação entre a renda total familiar e a contribuição da renda auferida da atividade na feira de hortifrutícolas do mercado municipal de Campos dos Goytacazes-RJ, 2016.

\begin{tabular}{|c|c|c|c|c|c|c|}
\hline & & \multicolumn{4}{|c|}{ Renda total da família } & \multirow[b]{2}{*}{ Total } \\
\hline & & $\begin{array}{c}\text { De } 1 \text { a } 2 \\
\text { s.m (R\$800 } \\
\text { a 1600) }\end{array}$ & $\begin{array}{c}\text { De } 2 \text { a } 3 \text { s. } \\
\text { m.R\$1600 } \\
\text { a 2400) }\end{array}$ & $\begin{array}{l}\text { Mais de } 4 \text { s. } \\
\text { m. (R\$3520) }\end{array}$ & $\begin{array}{l}\text { Não soube } \\
\text { ou não quis } \\
\text { responder }\end{array}$ & \\
\hline \multirow{3}{*}{$\begin{array}{c}\text { RENDA } \\
\text { EXTERNA }\end{array}$} & $50 \%$ & 0 & 0 & 3 & 0 & 3 \\
\hline & $75 \%$ & 1 & 1 & 0 & 0 & 2 \\
\hline & $100 \%$ & 14 & 11 & 6 & 1 & 32 \\
\hline TOTAL & & 15 & 12 & 9 & 1 & 37 \\
\hline
\end{tabular}

Fonte: Elaboração própria a partir dos resultados da pesquisa.

Nota: s.m. significa salário mínimo. 
De acordo com os resultados apresentados na Tabela 4, apenas três dos feirantes que disseram que $50 \%$ da renda total da família provinham da atividade na feira do mercado municipal de Campos também afirmaram que recebiam mais de quatro salários mínimos mensais. Quanto aos que relataram que $75 \%$ da renda total familiar era fruto da atividade na feira, um disse que recebia entre um e dois salários mínimos mensais e outro alegou que ganhava entre dois e três salários mínimos mensais.

Em relação aos feirantes entrevistados que afirmaram ter $100 \%$ da renda familiar oriunda da atividade da feira, 14 também disseram que recebiam entre um e dois salários mínimos mensais e 11 recebiam entre dois e três salários mínimos mensais, enquanto seis deles relataram que ganhavam mais do que quatro salários mínimos mensais e apenas um não soube ou não quis responder à questão. Então, o que se pode inferir a partir dos resultados apresentados na Tabela 4 é que a renda oriunda da atividade da feira era fundamental para a composição do orçamento familiar, pois em $86 \%$ dos casos era responsável por $100 \%$ do orçamento da família.

É importante destacar também a relação entre a forma como o feirante adquiriu a banca e se o mesmo era o proprietário da banca. Os resultados foram apresentados na Tabela 5.

TABELA 5 - Distribuição da relação entre a forma como o feirante adquiriu o direito de usar a banca na feira de hortifrutícolas do mercado municipal de Campos e se este é o proprietário da banca, 2016.

\begin{tabular}{|c|c|c|c|c|c|}
\hline & & \multicolumn{3}{|c|}{ Como adquiriu o direito de usar a banca } & \multirow[b]{2}{*}{ Total } \\
\hline & & Aluguel/Compra & Herança/Parentes & $\begin{array}{l}\text { Permissão do uso } \\
\text { do solo/doação } \\
\text { da prefeitura }\end{array}$ & \\
\hline \multirow{2}{*}{$\begin{array}{c}\text { PROPRIETÁRIO } \\
\text { DA BANCA }\end{array}$} & SIM & 4 & 22 & 6 & 32 \\
\hline & NÃO & 1 & 4 & 0 & 5 \\
\hline TOTAL & & 5 & 26 & 6 & 37 \\
\hline
\end{tabular}

Fonte: Elaboração própria a partir dos resultados da pesquisa.

Conforme Tabela 5, dos feirantes que disseram ser donos da banca, quatro alegaram que obtiveram o direito de usar a banca a partir de aluguel ou compra; neste caso, o feirante teve que arcar com um investimento inicial para conseguir exercer a atividade na feira. Dos demais que se disseram proprietários da banca, 22 afirmaram que receberam o direito de usar a banca a partir de herança ou através de algum parente, e os outros seis disseram que eram donos e que conseguiram usar o espaço no mercado municipal via permissão do uso do solo, que é uma espécie de licença ou doação da prefeitura. Quanto aos feirantes que alegaram não serem donos da banca, apenas um deles disse que obteve o direito de explorar comercialmente este espaço a partir de aluguel ou compra, enquanto quatro alegaram que, apesar de não serem donos da banca, receberam o direito de usar este espaço via herança ou intermédio de parentes. Por fim, observa-se que a maior parte dos feirantes que estavam nesta atividade, cerca de $70 \%$, sendo donos ou não da banca, atuava na feira por uma questão de tradição familiar, seja via herança ou intermédio de parentes. Isso demonstra que a atividade na feira do mercado municipal de fato se constitui uma herança sociocultural da cidade.

Outro ponto abordado neste estudo foram as características da residência dos feirantes, tanto no que tange à posse da casa onde moravam com sua família como a infraestrutura do imóvel. Dos entrevistados, $89,2 \%$ possuíam casa própria, enquanto $10,8 \%$ disseram que ainda nao haviam conseguido adquirir imóvel próprio para moradia. Informaram também que as residências, próprias ou não, eram de alvenaria.

Além disso, a maioria, $48,6 \%$ dos feirantes, residiam em casas que tinham entre quatro e cinco cômodos, que podem ser consideradas casas confortáveis. Outra parcela considerável, 43,2\% da amostra de feirantes, residia em casas com mais de cinco cômodos. Assim, o que pode-se 
inferir a partir dos resultados, é queas atividades desenvolvidas na feira, têm, de certa maneira, garantido a sobrevivência da família e permitido que os feirantes residamem imóveis capazes de garantir algum conforto em termos de espaço para seus familiares.

Quanto ao acesso a bens e serviços, as respostas dos entrevistados mostraram que $24,3 \%$ dos feirantes entrevistados tinham bens básicos, como geladeira, fogão, telefone e máquina de lavar. Outros $5,4 \%$ afirmaram que além dos bens básicos também possuíam computador. Ademais, 10,8\% dos feirantes que compuseram a amostra relataram que possuíam bens básicos e acesso a serviços como internet e, ou serviços bancários - que incluem conta corrente ou poupança e cartão de crédito - e, ou plano de saúde. Uma questão que se destaca é que $16,2 \%$ dos entrevistados afirmaram que possuíam os bens básicos e também uma relação de outros bens que demonstravam certo padrão de conforto, como automóvel, computador e freezer, além de acesso a serviços.

Ainda em relação à posse de bens e ao acesso a serviços, 75,7\% dos entrevistados tinham, além dos bens básicos, pelo menos algum acesso a serviços e, ou automóvel, e, ou computador e, ou freezer. Por fim, cabe mencionar que, quando perguntado se os bens e serviços foram adquiridos após o início da atividade na feira,51,4\% responderam que sim, enquanto $48,6 \%$ disseram que não. Com isso pode-se dizer que a atividade na feira permite aos feirantes obterem condição socioeconômica razoavelmente boa para satisfazerem as necessidades básicas de suas famílias.

Destaca-se ainda que, geralmente, os feirantes realizavam as vendas à vista e a receita auferida com a comercialização, combinada com outras rendas provenientes de outras fontes (aposentadorias, bolsa-família, migração sazonal, entre outras), permitiam aos mesmos consumirem bens e serviços na cidade. Assim, os ganhos das famílias feirantes eram transferidos semanalmente para os comerciantes e neste processo de circulação de riquezas, há geração de postos de trabalho e de renda. Por mais essa razão, acredita-se que políticas públicas voltadas a essa atividade poderiam contribuir para a diversificação produtiva no município, geração de emprego e renda, redução da desigualdade econômico-social.

\section{6- Conclusões}

Este artigo teve por objetivo analisar o perfil socioeconômico dos feirantes de hortifrutícolas que atuavam na feira do mercado municipal de Campos dos Goytacazes- RJ, com foco no papel que a feira desempenhava na formação da renda familiar e também nos mecanismos de comercialização presentes. $\mathrm{O}$ que se notou foi que, de modo geral, a atividade na feira tem característica familiar e é fundamental para que o feirante proporcione à sua família condições de vida digna. Além disso, os resultados obtidos com relação ao perfil socioeconômico dos feirantes confirmaram que uma parcela significativa da renda familiar dos feirantes de hortifrutícolas advém de suas atividades no mercado municipal de Campos, e que essa atividade é extremamente importante para eles, pois foi confirmado, por meio da pesquisa, que a maioria a tem como única fonte de renda. Cabe destacar que a pesquisa permitiu concluir que os feirantes que atuavam na feira de hortifrutícolas seguiram essa atividade por uma questão familiar, a exemplo, herança.

Observou-se que os feirantes de hortifrutícolas não eram os responsáveis pela produção dos produtos que comercializavam, e que esses produtos vinham de fora do município, por meio de fornecedores, caracterizando uma atividade que não adotava os circuitos curtos de comercialização.

Vale ressaltar que a feira se organizava em um local praticamente cedido pela prefeitura, o que é positivo, dado que o feirante não necessitava de grande volume de recursos para iniciar o negócio. Contudo, segundo os feirantes, este espaço não dispunha de boa estrutura e por isso surgiram muitas reclamações por parte dos mesmos, inclusive vários deles alegaram que se tivessem um local adequado para a venda de suas mercadorias isso os ajudaria a alavancarem seus negócios. Por estas razões e pela importância que a feira se mostrou para a composição do orçamento familiar, acredita-se que os feirantes são comerciantes natos e que se tivessem o devido apoio teriam muito 
mais condições para aumentarem sua rentabilidade, pois como se verificou, a partir das informações levantadas, os feirantes não possuíam assistência adequada de políticas públicas de incentivo à atividade que exerciam na feira. $\mathrm{E}$, com isso, muitas vezes os produtos locais não eram comercializados na feira e a dependência de intermediários acabava por aumentar os preços dos produtos, bem como contribuía para descaracterizar a feira de hortifrutícolas, que deveria ter por princípio básico a comercialização da produção local.

Contudo, vale ressaltar que, embora neste tipo de pesquisa, em que o objeto pesquisado- feirante, muitas vezes tenha se mostrado resistente em participar - principalmente quando a entrevista contém perguntas relacionadas à renda - e tenha acabado gerando informações não necessariamente fiéis à situação real, acredita-se que os resultados da pesquisa tenham levantado questões relacionadas à necessidade de se pensar sobre o que fazer para a produção da agricultura familiar alcançar os mercados locais como as feiras, já que este espaço é um canal de distribuição de livre acesso. Nesse caso, supõe-se que maior participação dos órgãos públicos locais poderia criar mecanismos de articulação com os produtores familiares, feirantes e até mesmo consumidores, para incentivar a comercialização de produtos da agricultura familiar. Então, como sugestão para pesquisas futuras, acredita-se ser fundamental a realização de estudos que investiguem as características da agricultura familiar no município e como essa se articula com os feirantes e possíveis gargalos que impedem ou reduzam tal articulação.

\section{Referências}

ANGULO, José Luis Gutiérez. Mercado local, produção familiar e desenvolvimento: um estudo de caso da feira de Turmalina, Vale do Jequitinhonha - MG. O. R. \& A. Revista de administração da UFLA - v.5 - n. 2 - julho/dezembro - 2003.

COÊLHO, Jackson Dantas. Feiras livres de Cascavel e de Ocara: caracterização, análise da renda e das formas de governanças dos feirantes. 2008. 151 f.: Dissertação (mestrado) - Universidade Federal do Ceará. Mestrado Acadêmico em Economia Rural (MAER). Centro de Ciências Agrárias. Fortaleza-CE. 2008.

COÊLHO, Jackson Dantas; PINHEIRO, José César Vieira. Análise das formas de governança dos feirantes que atuam nas feiras livres de Cascavel e de Ocara, no Ceará. In: XLVII Congresso da sociedade brasileira de economia, administração e sociologia rural, Porto Alegre - RS, 2009.

DELGADO, Guilherme. A questão agrária no Brasil, 1950-2003. In RAMOS, L.R.; ALY, O.J. (Eds.) Questão agrária no Brasil: perspectiva histórica e configuração atual. Instituto Nacional de Colonização e Reforma Agrária. São Paulo. 2005.

FONSECA, Fernando Sérgio Toledo de; BRAUNA, Ayrton Alves. A feira livre como um canal de distribuição de produtos rurais: um estudo de exploratório na feira livre de Araguaína, Tocantins. VIII Sober Nordeste, Novembro de 2013, Parnaíba - PI - Brasil.

FREITAS, Carlos Roberto Bastos. O mercado municipal de Campos dos Goytacazes: 86 anos de laços identitários e sociabilidade. Il colóquio internacional sobre o comércio e cidade uma relação de origem, 2006.

GIL, Antônio Carlos. Como elaborar projeto de pesquisa. 4a edição, editora Atlas, São Paulo, 2002.1. ed. 1987; 2. ed. 1989; 3. ed. 1991; 4. ed. 2002; 7atiragem.

GERHARDT, Tatiana Engel; SILVEIRA, Denise Tolfo (Org.). Métodos de Pesquisa. 1. ed. Porto Alegre: Editora da UFRGS, 2009. v. 1.118p.

GOMES, Almiralva Ferraz; SILVA, Joice de Souza Freitas; SANTOS, Adilson Almeida dos; SANTANA, Weslei Gusmão Piau; SANTOS, José Antonio Gonçalves dos. Perfil socioeconômico de mulheres fei- 
rantes: um estudo no interior baiano. IV encontro de administração política para o desenvolvimento do Brasil. Vitória da Conquista - Bahia, Junho de 2013.

MATTEI, Lauro. Programa Nacional de Fortalecimento da Agricultura Familiar (PRONAF): Concepção, abrangência e limites observados. Texto apresentado no IV Encontro da Sociedade Brasileira de Sistemas de Produção, realizado em Belém (PA), 2001.

MODEL, Patricia Aparecida; DENARDIN, Valdir Frigo. Agricultura Familiar e A Formação de Circuitos Curtos de Comercialização Através das Feiras Livres: O Caso da Matinfeira - PR. In: Encontro Internacional sobre Gestão Empresarial e Meio Ambiente, 2014, São Paulo. Anais do XVI Engema, 2014. v. 1. p. 1-14.

MORETTIN, Pedro Alberto; BUSSAB, Wilton de Oliveira. Estatística básica. [S.I: s.n.], 2004.

NARDINI, Monica da Silva.; CECCONELLO, Samanta Tolentino; ALTEMBURG, Shirley Grazieli Nascimento; SILVA, Fernando Novo da; BECKER, Claúdio. A agricultura familiar e os circuitos curtos de comercialização de alimentos: estudo de caso da feira livre do município de Jaguarão, RS, Brasil. Espacios (Caracas), v. 38, p. 7, 2017.

PIERRI, Maria Clara Queiroz Mauricio Pierri; VALENTE, Ana Lucia. E. F.A feira livre como canal de comercialização de produtos da agricultura familiar. In: XLVIII Congresso da Sober, 2010, Campo Grande. XLVIII Congresso da Sober, 2010.

ROCHA, Hélio Carlos; COSTA, Carlos; CASTOLDI, Florindo Luiz; CECCHETTI, Dileta; CALVETE, Eunice de Oliveira; LODI, Betânia dos Santos. Perfil socioeconômico dos feirantes e consumidores da Feira do Produtor de Passo Fundo, RS. Ciência Rural (UFSM. Impresso), v. 40, p. 2593-2597, 2010.

ROCHA, Hainnan Souza; SANT'ANA, Edvaldo Vieira Pacheco; SILVA, Eleyvam dos Santos. Caracterização socioeconômica dos feirantes da feira 304 Sul de Palmas - TO. 2014. In: Jornada de Iniciação Científica -Instituto Federal de Educação, Ciência e Tecnologia - IFTO, 2014, Dianópolis-TO. $5^{\text {a }}$ Jornada de Iniciação Científica - Instituto Federal de Educação, Ciência e Tecnologia - IFTO, 2014. v. 5.

SACCO DOS ANJOS, Flavio; GODOY, Wilson Itamar; CALDAS, Nádia Velleda. As feiras-livres de Pelotas sob o império da globalização: perspectivas e tendências. Pelotas: Editora e gráfica Universitária. 2005.

SALES, Aline Pereira; REZENDE, Liviane Tourino; SETTE, Ricardo de Souza. Negócio feira livre: um estudo em um município de Minas Gerais. III Encontro de gestão de pessoas e relações de trabaIho. João Pessoa - PB - 20 a 22 de novembro de 2011.

SILVESTRE, Luiz Henrique Aparecido; RIBEIRO, Áureo Eduardo Magalhães; FREITAS, Camila da Silva. Subsídios para a construção de um programa público de apoio à feira livre no vale do São Francisco, MG. Organizações Rurais \& Agroindustriais. V. 13(2). 2011.186-200.

WANDERLEY, Maria de Nazareth Baudel. A Agricultura Familiar No Brasil:Um Espaço Em Construção. Reforma Agrária, CAMPINAS, v. 25, n.2/3, p. 37-57, 1995.

WILKINSON, John. Mercados, Redes e Valores. O novo mundo da agricultura familiar. Porto Alegre: Ed. UFRGS, 2008 (p.125-170). 